\title{
Human Breast Milk Bank: Valuable Issue for Working Mothers
}

\author{
Hanan Elzeblawy Hassan
}

Maternal and Newborn Health Nursing, Faculty of Nursing, Beni-Suef University, Egypt, nona_nano_1712@yahoo.com

\section{Introduction}

Breast-milk is a dynamic body-fluid that changes in its composition to meet the nutritional requirements of the newborns, provides protection from infectious disease, and promotes neurodevelopment. UNICEF \& WHO recommend that newborn should be breastfed, exclusively, for the first 4 to 6 months of life. However, worldwide, few infants are breastfed exclusively for more than a few weeks, even in countries/societies where breastfeeding is still the norm. Some mothers worry about the amount of breast milk they produce as early as the first day's post-partum. Almost all mothers can produce enough breast-milk for 1 or even 2 babies. There is however occasions when a baby does not get enough breast milk such as, he isn't suckling enough, not suckling effectively or the mother is unable to produce enough milk because of poor mammary gland development or hormone disturbance. $(1,2,3,4)$

\section{Human-Mothers-Milk-Banks}

Human mothers milk is specifically designed for human babies and provides unique benefits that can't be duplicated by formula. Human-milk provides babies with antibodies to fight disease and infection. Additionally, it protects against allergies. Anywhere it isn't possible for the mother to breastfeed, the 1st alternative, if available, should be the use of human-milk from other sources. Human-milk-banks should be made available in appropriate situations. Providing fragile infants with pasteurized human donor milk provides them with passive immunity and gives them a stronger hold on life. ${ }^{(5,6,7,8)}$

\section{What is Milk-Banks?}

A milk bank screens, collects, processes and dispenses donated human-milk as a community service, providing human-milk to infants whose own mothers can't supply the milk to meet their baby's needs. A milk bank is also a resource for health professionals and the general public in the uses and benefits of human milk, the standard in infant feeding. ${ }^{(9)}$ So, the, donor Human-Milk-Banks is a service established for the purpose of collecting, screening, processing, and distributing donated human-milk to meet the specific medical needs of individuals for whom it is prescribed. ${ }^{(10)}$

There are currently 12 operating milk banks in the United States and 2 in Canada. There are 4 developing milk banks in the United States while, in the UK there are 17 main milkbanks.

\section{Bank guideline}

It serves as a practical guide to the effective running of these services. It makes a series of recommendations designed to promote consistent standards of practice across the country and ensure the safety of donor breast milk. ${ }^{(11)}$

Donor milk banks receive milk from lactating mothers with excess milk supply to be eligible to donate; potential donors first participate in a multi-step screening process similar to a blood-bank. These steps include donor's practices as lifestyle screening questionnaire, blood borne virus serology, educated in hygienic collection, storage, transport of breast milk and formal donor consent procedure with each donation. ${ }^{(12)}$

The guideline is primarily aimed at milk banking staff and healthcare professionals who support women who are, or who want to become, breast-milk donors or who care for patients who may be given the milk. These include, but aren't limited to, midwives, health-visitors and neonatologists. Recommendations include: ${ }^{(13)}$

- Using serological testing to screen all potential breastmilk-donors for diseases including HIV, hepatitis and syphilis. This is to ensure those who test positive don't

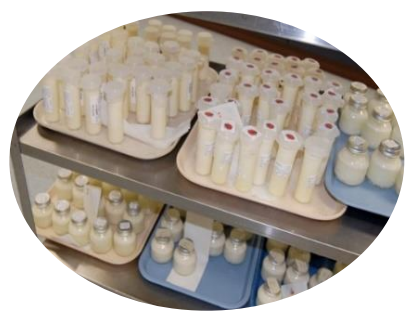


become breast-milk-donors because of the risk of these diseases being spread through breast-milk.

- Pasteurizing all milk to reduce the risk of any potentially harmful bacteria being passed on. A sample from each batch of donated breast milk should be tested for bacterial contamination before pasteurization and at regular intervals post pasteurization. Milk should be discarded if samples exceed levels stated in the guideline.

- Ensuring that all equipment used in milk-handling and processing is regularly inspected using the manufacturer's instructions.

- Only supplying donor breast-milk to hospitals or newborn units who agree to comply with the tracking procedures for milk as outlined by the milk-banks. The receiving hospital or newborn unit should also keep a record of how the milk is used.

Volunteer-donors pump extra milk into sterile containers and freeze it. The raw donor-milk is transported to the milk bank frozen. The milk from several donors is pooled after thawing, then heat-treated to kill bacteria and viruses and frozen (pasteurized). It is only dispensed after a sample is cultured and shows no bacteria growth. Milk is shipped frozen by overnight express to hospitals and to individual recipients at home. ${ }^{(14)}$

\section{Pasteurization (12)}

Boiling sterilizes milk but removes many of the desirable factors. Pasteurization preserves many nutrient and biologically active factors. Heat milk to $62.5^{\circ} \mathrm{C}$ for 30 minutes in water bath, then rapid cooling $<10^{\circ} \mathrm{C}=$ Holder pasteurization.

\section{Volunteer donors 'characteristics $(12,14,15)$}

Volunteer donors must be: -
- In good health

- Non-smoker.

- Non-alcohol consumer.

- Often they are nursing their own baby and have surplus milk.

- Not known to have or had any Blood Borne Virus, and willing to undergo blood testing (at the milk bank's expense).

- Taking no medications or herbs during the time, the milk is pumped. (with the exception of prenatal vitamins, human insulin, thyroid replacement hormones, nasal sprays, asthma inhalers, topical treatments, eye drops, progestin-only or low dose estrogen birth control products.

- Have a baby less than six months old when donations begin.

\section{Volunteer donors mustn't be: - (4)}

- Uses illegal drugs

- Smokes or uses tobacco products

- Received a blood transfusion or blood products in the last 4 months

- Received an org a $\mathrm{n}$ or tissue transplant in the last year.

- Regularly has more than two ounces of alcohol/day

- A positive blood test result for HIV, HTLV, hepatitis B or $\mathrm{C}$, or syphilis

- Her sexual partner is at risk for HIV.

Human donor milk will be provided for: ${ }^{(11)}$

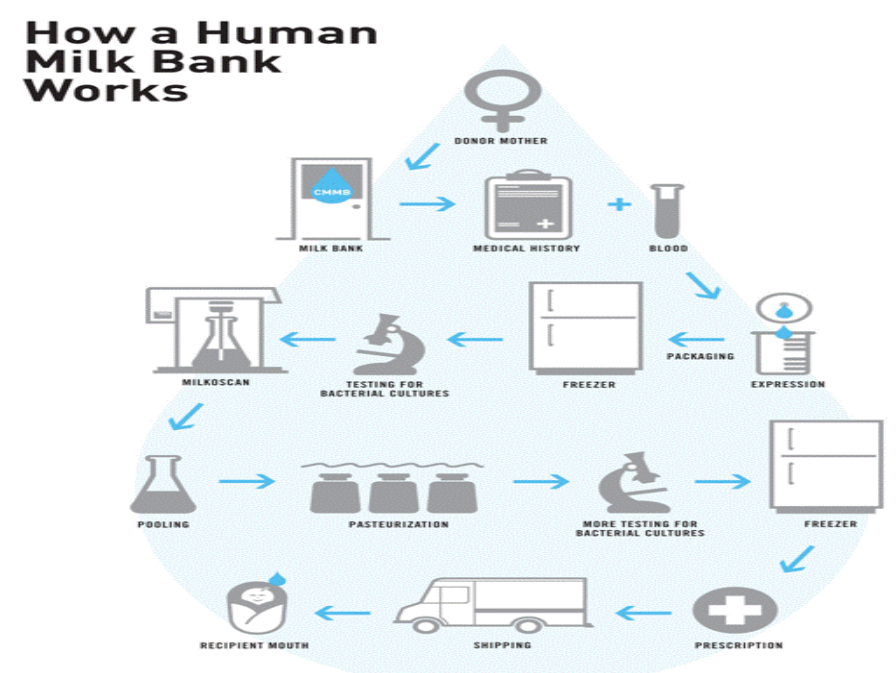


- $\quad$ Preterm $<32$ weeks' age at birth

- $\quad \mathrm{VLBW}<1500$ gm birth weight

- babies in the neonatal intensive care unit (NICU)

- $\quad$ Post-operative, short gut syndromes

- babies who are failing to thrive on formula

- Post Necrotizing Enterocolitis

- Children and toddlers with life-threatening diseases or conditions

- Malabsorption syndromes

- multiple birth babies whose moms can't keep up with the milk required to nourish their infants

- babies of mothers whose milk isn't suitable for consumption due to disease or prescription medications that pass through the milk.

\section{Conclusion:}

Expected mothers can save the life her baby if she has the information regarding human mothers bank especially if she or her baby have any health problem can prevent the normal process of breast feeding and at the same time can threat his life especially if there is no another natural source of breast milk. But she must decide as early as possible to contact the human mothers bank, also newly mothers can do it. So, we recommended that the information must be easily available during antenatal classes.

\section{References}

1. American Academy of Pediatrics (AAP) (2005): Breastfeeding and the use of human milk, Pediatrics; 115(2): 496- 506.

2. Abd-Allah N., Nasr E., Hassan H. Impact of a Breast Feeding Educational Program for Mothers Having Pre-Term Infants in General Hospitals in Port Said. International Journal of Novel Research in Healthcare and Nursing, 2017; 4, (3): 215-225.

3. WHO/ UNICEF declaration, 1980

4. Faheim S. , Hassan H. , Gamel W. Topical Application of Human Milk versus Alcohol and Povidine-Iodine on Clinical Outcomes of Umbilical Cord in Healthy Newborn: Impact of an Educational Program of Mothers' Knowledge and Practice Regarding Umbilical Cord Care.International Journal of Studies in Nursing, 2019; 4(2): 35-51. doi:10.20849/ijsn. $\mathrm{v} 4 \mathrm{i} 2.573$
5. Human Milk Banking Association of North America, Donate Milk, Sharing milk through a non-profit milk bank saves lives

6. Hassan H., Gamel W., Hassanine Sh., Sheha E. Fenugreek Seed Poultice versus Cold Cabbage Leaves Compresses for Relieving Breast Engorgement: An interventional Comparative Study. Journal of Nursing Education and Practice. 2020; 10(5): 82-99. doi: 10.5430/jnep.v10n5p82

7. Hassan H., EL-Kholy G., Ateya A., Hassan A. Breast Feeding Knowledge and Practices among Primiparous Women with Caesarean Section: Impact on Breast Engorgement in Upper Egypt. Communication, Society and Media, 2020; 3(2): 34- 78 .

8. Zagloul M., Naser El., Hassan H. Influence of Hot Compresses Versus Cabbage Leaves on Engorged Breast in Early Puerperium. International Journal of Studies in Nursing, 2020; 5(2): 7-14. doi:10.20849/ijsn.v5i2.740

9. Hassan H., EL-Kholy G., Ateya A. \& Hassan A. Breast Engorgement among Women with Caesarean Section: Impact of Nursing Intervention. Education, Society and Human Studies, 2020; 1(2): 22-55. doi:10.22158/ eshs.v1n2p22

10. The Best Start - Report on the inquiry into the health benefits breastfeeding. House of Representatives Standing Committee on Health and Ageing, 2007. www.aph.gov.au/house/committee/haa/breastfeeding/index.htm

11. http://www.ukamb.org/yourmilkbank.html

12. www.nice.org.uk/guidance/CG93

13. The clinical guideline, "Donor breast milk banks: the operation of donor breast milk bank services" is available at: http://guidance.nice.org.uk/ CG93 from Wednesday 24 February 2010.

14. Human Milk Banking Association of North America: http://www.hmbana. org/index.php?mode $=$ faq

15. Mothers' Milk Bank: http://www.bestfedbabies.org/mDonate.htm 